\title{
Temporal lobe epilepsy with mesial temporal sclerosis: hippocampal neuronal loss as a predictor of surgical outcome
}

\author{
Epilepsia do lobo temporal com esclerose mesial temporal: o padrão da perda neuronal \\ hipocampal como preditor do prognóstico cirúrgico \\ Anaclara Prada Jardim¹, Rafael Scarpa da Costa Neves', Luís Otávio Sales Ferreira Caboclo', Carmen Lucia \\ Penteado Lancellotti2,3, Murilo Martinez Marinho ${ }^{1}$, Ricardo Silva Centeno ${ }^{1}$, Esper Abrão Cavalheiro ${ }^{4}$, Carla \\ Alessandra Scorza4 , Elza Márcia Targas Yacubian
}

\begin{abstract}
Objective: To analyze retrospectively a series of patients with temporal lobe epilepsy (TLE) and mesial temporal sclerosis (MTS), and the association of patterns of hippocampal sclerosis with clinical data and surgical prognosis. Method: Sixty-six patients with medically refractory TLE with unilateral MTS after anterior temporal lobectomy were included. Quantitative neuropathological evaluation was performed on NeuN-stained hippocampal sections. Patient's clinical data and surgical outcome were reviewed. Results: Occurrence of initial precipitating insult (IPI), as well as better postoperative seizure control (i.e. Engel class 1), were associated with classical and severe patterns of hippocampal sclerosis (MTS type 1a and 1b, respectively). Conclusion: Quantitative evaluation of hippocampal neuronal loss patterns predicts surgical outcome in patients with TLE-MTS.
\end{abstract}

Key words: epilepsy, temporal lobe, mesial temporal sclerosis, hippocampal sclerosis, pathology, surgical prognosis.

\section{RESUMO}

Objetivo: Analisar retrospectivamente uma série de pacientes com epilepsia do lobo temporal (ELT) e esclerose mesial temporal (EMT), bem como correlacionar os padrões de esclerose hipocampal com os dados clínicos e o prognóstico cirúrgico. Métodos: Foram incluídos neste estudo 66 pacientes com ELT refratária a tratamento medicamentoso e com EMT unilateral submetidos à lobectomia temporal anterior. A análise neuropatológica quantitativa foi realizada em seções hipocampais imunomarcadas com NeuN. Dados clínicos e resultados do acompanhamento pós-cirúrgico foram revisados. Resultados: Ocorrência de evento precipitante inicial e melhor controle de crises após a cirurgia (i.e. classe 1 de Engel) foram associados aos padrões clássico (EMT tipo 1a) e severo (EMT tipo 1b) de esclerose hipocampal. Conclusão: A análise quantitativa do padrão de perda neuronal do hipocampo é capaz de predizer o prognóstico cirúrgico em pacientes com ELT-EMT.

Palavras-Chave: epilepsia do lobo temporal, esclerose mesial temporal, esclerose hipocampal, patologia, prognóstico cirúrgico.

Mesial temporal sclerosis (MTS) is the most common pathological finding in drug refractory, chronic temporal lobe epilepsy (TLE) ${ }^{1}$. Mesial temporal lobe structures with a sclerotic hippocampus have been considered the site of seizure onset for most TLE patients, and hippocampal sclerosis (HS) has been considered essential for MTS diagnosis. Surgery has become the treatment of choice in the management of patients with this epilepsy syndrome ${ }^{2,3}$. Tailored resections of temporal neocortex and mesial temporal structures, including hippocampus and amygdala, are an established epilepsy treatment modality and offer a favorable outcome in approximately two-thirds of patients ${ }^{4,5}$.

The reason why around one-third of individuals with this epilepsy syndrome still present seizures after surgical treatment

\footnotetext{
${ }^{1}$ Department of Neurology and Neurosurgery, Escola Paulista de Medicina, Universidade Federal de São Paulo (UNIFESP), São Paulo SP, Brazil;

${ }^{2}$ Department of Pathology, Santa Casa de São Paulo, São Paulo SP, Brazil;

${ }^{3}$ Department of Pathology, Medical Diagnosis, Associação Fundo de Incentivo à Pesquisa (AFIP), São Paulo SP, Brazil;

${ }^{4}$ Department of Neurology and Neuroscience, Experimental Neurology, Escola Paulista de Medicina, UNIFESP, São Paulo SP, Brazil.

Correspondence: Anaclara Prada Jardim; Unidade de Pesquisa e Tratamento das Epilepsias; Rua Napoleão de Barros 737 / 130 andar; $04024-002$ São Paulo SP Brasil; E-mail: anaclarapjardim@gmail.com

Support: This work was partly funded by Fundação de Amparo à Pesquisa do Estado de São Paulo (FAPESP) and Conselho Nacional de Desenvolvimento Científico e Tecnológico (CNPq, Brazil).

Conflict of interest: There is no conflict of interest to declare.

Received 25 November 2011; Received in final form 05 January 2012; Accepted 13 January 2012
} 
has been a matter of debate ${ }^{6}$. Among other factors, it has been suggested that different patterns of neuronal cell loss within hippocampal subfields may be implicated in surgical results ${ }^{6,7}$.

The aim of this study was to analyze retrospectively a series of 66 patients with TLE and MTS, as well as investigate the association of clinical data, patterns of HS and surgical prognosis.

\section{METHODS}

\section{Subjects}

Sixty-six consecutive patients, 33 men (50.0\%), mean age $37 \pm 11.41$ years, with medically refractory TLE with unilateral MTS on MRI, 36 (54.5\%) with right- and 30 (45.5\%) with left-hippocampal resections, were included in this study. Diagnosis was established according to previously reported clinical and electrographic characteristics ${ }^{2}$. Patients who did not achieve seizure control despite of adequate use of at least two first-line antiepileptic drugs (AEDs), in mono or polytherapy, and up to toxic levels, were qualified as medically refractory. The study was approved by the Ethics Committee of our institution (CEP 2009/10) and informed consent was given from all patients.

Clinical features were retrospectively recorded according to a specific protocol developed for this study. Presence and age of initial precipitant insult (IPI) defined by Mathern et al. ${ }^{8}$, age at onset of habitual seizures, defined as the age at which habitual and recurrent seizures developed, as well as duration of epilepsy, were registered. The duration of epilepsy was defined as the interval between the age at onset of habitual seizures and the time of surgery. Average frequency of preoperative complex partial seizure per month and the mean number of generalized tonic-clonic seizures (GTCS) throughout lives, classified in $>$ or $<20$, were also registered.

All patients had extensive presurgical evaluation including high-resolution 1.5T MRI (Siemens Somaton or Phillips Gyroscan equipment), prolonged non-invasive video-EEG recording and neuropsychological testing. All patients had clear MRI findings consistent with unilateral MTS, defined as variable degrees of HS (atrophy, increased T2 and decreased T1-weighted signal, and disrupted internal structure of the hippocampus), atrophy and signal alteration of amygdala and temporal pole on visual inspection of MRI pictures. Patients with unilateral MTS associated with additional abnormalities besides brain atrophy detected by visual inspection were excluded.

Prolonged non-invasive video-EEG monitoring was performed on a 32-channel digital equipment (Biologic and Ceegraph software). Electrodes were placed according to the 10-20 International System, plus intermediary temporal and sphenoidal electrodes. In order to record ictal events, AEDs were tapered off or completely withdrew at physician's discretion. The frequency and location of interictal epileptiform discharges were visually assessed on 5-minute EEG samples per hour, 24 hours per day, and ictal EEG recordings were also analyzed.
When concordant data was obtained in this evaluation, including neuropsychological assessment, a surgical resection was performed. Surgical procedure consisted on a resection of $3.5 \mathrm{~cm}$ of temporal neocortex from temporal pole on dominant hemisphere ( $4.5 \mathrm{~cm}$ from the non-dominant) associated with a $3.5 \mathrm{~cm}$ resection of hippocampus and two-thirds of amygdala. All patients were followed-up for at least six months after surgery, and seizure control was defined according to Engel classification ${ }^{4}$.

\section{Tissue preparation}

The hippocampi of all patients were collected from the period of 2005 to 2011 from the archives of neuropathology, and those with less than three subfields or without CA1 and/or CA4 sectors represented in the tissue were excluded.

Five-mm-thick slices along the hippocampus anteroposterior axis were dissected, fixed overnight in $4 \%$ formalin and processed into liquid paraffin. A single block corresponding to the mid hippocampal body was selected from each case for histopathological examination ${ }^{9}$ and cut at $7 \mu \mathrm{m}$ (Leica, Germany), expanded in hot water, mounted on slides coated with silane and air-dried at $56^{\circ} \mathrm{C}$ overnight in an incubator. Two slides of each case were deparaffined in xylol and descending alcohol concentration. One was stained with hematoxylin and eosin (HE) for pathological diagnosis, and the other was submitted to an automated staining apparatus (Autostainer Link 48, Dako, USA) for NeuN immunohistochemistry (Chemicon, Temecula, USA, dilution 1:1000, pretreated in PT Link equipment, Dako, USA) and counterstaining with hematoxylin. All tissue specimens were qualitative and quantitative analyzed by two independently observes (AJ and RN) both in NeuN and HE stained slides.

Thirteen hippocampi specimens obtained from autopsy of neurologically healthy subjects without a history of epilepsy served as controls (mean age 57.6 \pm 14.34 years). $\mathrm{HE}$ and NeuN staining method were carried out on the postmortem tissue. There was no difference accuracy between control's HE- and NeuN-stained sections as reported in previous studies ${ }^{6,7}$.

\section{Neuronal cell counts}

All epilepsy tissue and controls specimens were analyzed according to Blümcke et al. ${ }^{7}$. Microscopically images were obtained utilizing an E600 microscope equipped to Moticam 2300 camera (Nikon, Japan). Measurements of neuronal cells were performed on ImageJ software (National Institutes of Health, NIH, USA). Immunohistochemically stained neuronal cell bodies were visualized on the computer screen (Motic images plus software). Hippocampal subfields were identified using $2 \mathrm{x}$ objective lens, and four randomly regions in each sector (CA1 - CA4), representing $0.0625 \mathrm{~mm}^{2}$, were outlined. Within these visual fields, all NeuN-positive neurons, despite size and morphology differences, were counted at objective 20x. For each subfield, neuronal cell density was calculated (neurons x $10^{-4} / \mu \mathrm{m}^{2}$ ). 


\section{Statistical analysis}

Values of neuronal cell counts from each hippocampal subfield were transformed into Z-scores. Z-score is the number of standard deviation from the mean expected value, which in this case is the mean controls subfields density values, and is calculated according to $\mathrm{Z}=$ (score - mean of the control)/standard deviation of the control population. Results that are more than two standard deviation away from the mean expected value were considered abnormal; only negative Z-scores were relevant. The different patterns of HS were determined according to $\mathrm{to}^{6}$ : no MTS, Z-score $<2$ in all hippocampal subfields; MTS type 1a, Z-score $<2$ in CA2, but $>2$ in remain sectors; MTS type $1 \mathrm{~b}$, Z-score $>2$ in each subfield; MTS type 2, Z-score $>2$ in CA1 and $<2$ in CA4; MTS type 3, Z-score $>2$ only in CA4.

To analyze the importance of clinical data on the different patterns of HS, variance analysis with one-way ANOVA was chosen. Statistical evaluation was carried out in SPSS 10.0 for Windows, version 10.01 , and $p$ values $<0.050$ were considered as statistical significant.

\section{RESULTS}

In our series of 66 patients, four distinct patterns of HS were recognized as suggested in a previous study ${ }^{7}$ : no MTS $(\mathrm{n}=3,4.5 \%$, Fig $1 \mathrm{~A})$, MTS type 2 ( $\mathrm{n}=4,6.1 \%$, Fig $1 \mathrm{~B})$, MTS type $1 \mathrm{a}(\mathrm{n}=18,27.3 \%$, Fig $1 \mathrm{C})$ and MTS type $1 \mathrm{~b}(\mathrm{n}=41,62.1 \%$, Fig 1D). Atypical end folium sclerosis (MTS type 3) was not found in this cohort of surgical specimens.

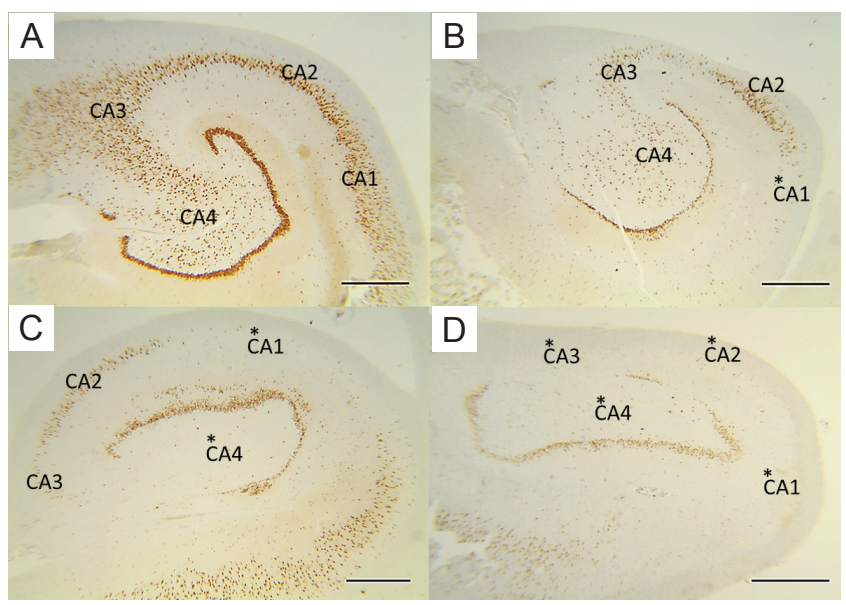

MTS: mesial temporal sclerosis; HS: hippocampal sclerosis.

Fig 1. Patterns of hippocampal sclerosis (all NeuN-stained sections). (A) No MTS. No loss of neurons detected in all subfields (CA1-CA4). (B) MTS type 2 (CA1-sclerosis). Predominant neuronal loss in CA1 subfield. (C) MTS type 1a (classic hippocampal sclerosis). Significant neuronal loss from CA1 and CA4 with better preservation of neurons in CA2. (D) MTS type $1 \mathrm{~b}$ (severe hippocampal sclerosis). Total HS with neuronal loss in all subfields and in the dentate gyrus. Scale bars $1 \mathrm{~mm}$. *For regions with significant cell loss.

\section{Neuropathological analysis}

In any MTS group, hippocampal subfields neuronal cell densities were similar as compared to autopsy control values (within first fold standard deviation, Fig 2).

In MTS type 1a, the CA1 and CA4 subfields were the most affected (mean neuronal densities ranging from $20.6 \% \pm 7.8 \%$ in CA1 and $27.5 \% \pm 13.7 \%$ in CA4 compared to controls, Table 1) while in MTS type $1 \mathrm{~b}$ a severe neuronal loss in all hippocampal subfields with a mean loss of 70 to $80 \%$ was observed (neuronal densities in CAl $=0.54 \pm 0.249 \times 10^{-4}$ neurons $/ \mu \mathrm{m}^{2}$, $\mathrm{CA} 2=0.98 \pm 0.602 \times 10^{-4}$ neurons $/ \mu \mathrm{m}^{2}, \mathrm{CA} 3=0.76 \pm 0.413 \times 10^{-4}$ neurons $/ \mu \mathrm{m}^{2}, \mathrm{CA} 4=0.51 \pm 0.346 \times 10^{-4}$ neurons $\left./ \mu \mathrm{m}^{2}\right)$ (Table 1 ).

MTS type 2, an atypical pattern of severe neuronal loss almost restricted to subfield CA1, presented a mean cell density of $15.0 \% \pm 5.3 \%$ compared to control values (Table 1 ), but only a mild decrease in CA2, CA3 and CA4 (first to second standard deviation, Fig 2).

\section{Clinipathological association}

Gender, side of resection, age at surgery and mean age at epilepsy onset were closely similar among patients with distinct patterns of HS. Monthly seizure frequency and estimated lifetime GTCS did not show influence on severity of hippocampal cell loss (data not shown). Although not statistically significant, there were differences in mean duration of epilepsy between the MTS patterns (Table 2), with shortest duration of epilepsy to surgery for no MTS patients.

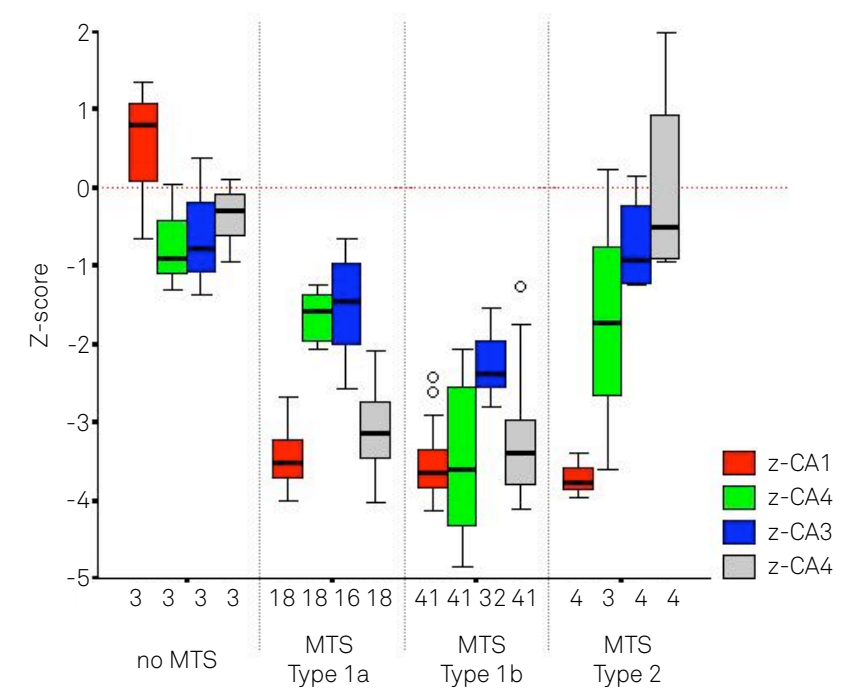

Fig 2. Distinct patterns of hippocampal sclerosis could be identified in this series from the analysis of z-scores: no MTS, neuronal cell loss within the first standard deviation compared to controls (Z-score <2 in each subfield); MTS type 1a, significant cell loss detected in CA1 and CA4 (Z-score $>2$ ) with preservation of neurons in remain sectors (Z-score <2); MTS type $1 \mathrm{~b}$, severe hippocampal sclerosis in all subfields (Z-score > 2 in CA1-CA4); MTS type 2, significant loss of neurons restricted to CA1-sector and only mild pathology within the other hippocampal subfields (Z-score <2 in CA2, CA3 and CA4).Z-CA1-CA4, Z-score of CA1-CA4; open circles, patients which scape from the determining patterns. MTS: mesial temporal sclerosis. 
Table 1. Pathology measurement data.

\begin{tabular}{|c|c|c|c|c|}
\hline & CA1 mean (SD) & CA2 mean (SD) & CA3 mean (SD) & CA4 mean (SD) \\
\hline \multicolumn{5}{|c|}{ Neuronal cell densities (neurons $\times 10^{-4} / \mu m^{2}$ ) } \\
\hline No MTS & $3.20(0.682)$ & $2.84(0.472)$ & $2.60(0.956)$ & $1.92(0.262)$ \\
\hline MTS type 1a & $0.59(0.223)$ & $2.21(0.196)$ & $1.60(0.683)$ & $0.58(0.288)$ \\
\hline MTS type $1 b$ & $0.54(0.249)$ & $0.98(0.602)$ & $0.76(0.413)$ & $0.51(0.346)$ \\
\hline MTS type 2 & $0.43(0.151)$ & $2.17(1.300)$ & $2.44(0.712)$ & $2.11(0.671)$ \\
\hline Controls & $2.87(0.655)$ & $3.33(0.678)$ & $3.24(1.085)$ & $2.11(0.492)$ \\
\hline \multicolumn{5}{|c|}{ Neuronal density expressed as proportion (x 100) of control values } \\
\hline No MTS & $111.4 \%(23.8)$ & $85.3 \%(14.2)$ & $80.2 \%(29.5)$ & $91.1 \%(12.5)$ \\
\hline MTS type 1a & $20.6 \%(7.8)$ & $66.4 \%(5.9)$ & $49.3 \%(21.1)$ & $27.5 \%(13.7)$ \\
\hline MTS type $1 \mathrm{~b}$ & $18.9 \%(8.7)$ & $29.5 \%(18.1)$ & $23.5 \%(12.7)$ & $24.3 \%(16.4)$ \\
\hline MTS type 2 & $15.0 \%(5.3)$ & $65.3 \%(39.0)$ & $75.3 \%(22.0)$ & $100.2 \%(31.9)$ \\
\hline
\end{tabular}

MTS: mesial temporal sclerosis; SD: standard deviation.

Table 2. Clinical data in MTS patterns.

\begin{tabular}{lccc} 
& $\begin{array}{c}\text { Mean age of } \\
\text { epilepsy onset } \\
\text { (SD) years }\end{array}$ & $\begin{array}{c}\text { Mean age at } \\
\text { surgery (SD) } \\
\text { years }\end{array}$ & $\begin{array}{c}\text { Mean duration } \\
\text { of epilepsy } \\
\text { (SD) years }\end{array}$ \\
\hline $\begin{array}{l}\text { No MTS } \\
\text { N=3 (4.5\%) }\end{array}$ & $19.0(6.56)$ & $28.3(10.60)$ & $9.3(4.62)$ \\
MTS type 1a & $13.0(10.55)$ & $38.0(10.15)$ & $25.6(13.76)$ \\
N=18(27.3\%) & $14.4(9.23)$ & $37.6(12.10)$ & $23.1(12.85)$ \\
MTS type 1b & & & \\
N=41 (62.1\%) & $16.5(14.39)$ & $34.5(10.75)$ & $18.0(11.17)$ \\
MTS type 2 & & & \\
N=4 (6.1\%) & $p=0.632$ & $p=0.514$ & $p=0.171$ \\
\hline
\end{tabular}

Statistical analysis carried out between MTS groups. MTS: mesial temporal sclerosis; N: number of patients; SD: standard deviation.
Table 3. Histopathological patterns of hippocampal sclerosis and history of preceding events.

\begin{tabular}{lcccc} 
& IPI (N) & FS (N) & $\begin{array}{c}\text { Mean age at } \\
\text { IPI (SD) years }\end{array}$ & $\begin{array}{c}\text { Latency } \\
(\mathrm{SD}) \text { years }\end{array}$ \\
\hline No MTS & $0.0 \%$ & - & - & - \\
MTS type 1a & $44.4 \%(8)$ & $50.0 \%(4)$ & $1.8(1.37)$ & $12.0(6.76)$ \\
MTS type 1b & $63.4 \%(26)$ & $38.5 \%(10)$ & $1.8(1.43)$ & $11.6(7.12)$ \\
MTS type 2 & $0.0 \%$ & - & - & - \\
& $\mathrm{p}=0.011$ & $\mathrm{p}=0.689$ & $\mathrm{p}=0.789$ & $\mathrm{p}=0.984$ \\
\hline
\end{tabular}

MTS type 2 and patients without MTS experienced no IPI. Statistical analysis carried out between MTS groups. MTS: mesial temporal sclerosis; IPI: initial precipitating insult; FS: febrile seizure; N: number of patients.

Table 4. Histopathological patterns of hippocampal sclerosis and postsurgical outcome.

\begin{tabular}{lccccc} 
& Engel 1 (N) & Engel 2 (N) & Engel 3 (N) & Engel 4 (N) & Total (N) \\
\hline No MTS & $0.0 \%(0)$ & $33.3 \%(1)$ & $33.3 \%(1)$ & $33.3 \%(1)$ & $100 \%(3)$ \\
MTS type 1a & $83.3 \%(15)$ & $16.7 \%(3)$ & $0.0 \%(0)$ & $0.0 \%(0)$ & $100 \%(18)$ \\
MTS type 1b & $75.6 \%(31)$ & $14.6 \%(6)$ & $4.9 \%(2)$ & $4.9 \%(2)$ & $100 \%(41)$ \\
MTS type 2 & $50.0 \%(2)$ & $25.0 \%(1)$ & $25.0 \%(1)$ & $0.0 \%(0)$ & $100 \%(4)$ \\
Total & $72.7 \%(48)$ & $16.7 \%(11)$ & $6.1 \%(4)$ & $4.5 \%(3)$ & $100 \%(66)$ \\
p=0.034 & & & & &
\end{tabular}

Values expressed as percentage of total for the mesial temporal sclerosis (MTS) groups in surgical outcome proposed by Engel et al. (1993). No MTS group was associated with the poorest outcome. MTS types $1 \mathrm{a}$ and $1 \mathrm{~b}$ presented best postsurgical seizure control, while MTS type 2 had only $50 \%$ seizure relief. N: number of patients.

Within the surgical patients, 34 (51.5\%) reported a history of initial precipitating insult (IPI) of whom $14(41.2 \%)$ experienced complex febrile seizures, $12(35.3 \%)$ afebrile seizures, five (14.7\%) meningitis and three (8.8\%) head trauma. Occurrence of an IPI was not reported among MTS type 2 and cases with no HS (Table 3). The age of IPI and the latent period between the preceding event and the onset of habitual seizures was not significantly different.

Forty-eight patients (72.7\%) became seizure-free after surgery. The poorest outcome occurred in patients with normal hippocampal cell densities (no MTS) with all of them still presenting seizures at the last follow-up visit after surgery (Table 4). Better outcomes were observed for the MTS type la and MTS type $1 \mathrm{~b}$ cases, with seizure relief ranging from 75.6 to $83.3 \%$. Only $50.0 \%$ of patients with MTS type 2 achieved seizure freedom, while $25.0 \%$ patients remain showing rare disabling seizures (Engel 2) and the other $25.0 \%$ had a worthwhile improvement (Table 4).

\section{DISCUSSION}

Up to one-third of individuals with TLE still present seizures after surgical treatment ${ }^{10,11}$. The identification of prognostic factors in an attempt to better predict postoperative 
outcome is critical to select the best surgical candidates and to improve clinical management of epilepsy surgery.

The agreement records of the MRI, ictal and interictal EEG, neuropsychological tests and positron emission tomography pointing to a unilateral and localized epileptogenic zone have already been shown to favor surgical prognosis ${ }^{12-14}$.

Histopathological evaluation of the surgical specimens have also been suggested as a predictor of postoperative seizure control ${ }^{6,7,15}$. A favorable outcome has been related to a greater degree of hippocampal atrophy neuropathologically diagnosed as classical HS 7,13,16. Otherwise, the atypical patterns of hippocampal neuronal loss may predict poorer outcome $e^{7,15,17}$. The identification of distinct patterns of HS may suggest different clinical histories and epileptogenic pathways, and disassociate HS as a single condition.

In this study, we applied a quantitative analytical method to determine the patterns of HS, according to Blümcke's classification ${ }^{7}$, in our surgical series. Despite electrophysiological evidence for TLE, three surgical specimens did not present specific neuronal cell loss. This finding has been reported in similar surveys ${ }^{1,6,7,15,18}$ and no long has been explained.

Despite our small cohort of patients, this is a pure series of TLE-MTS since individuals with a second potentially epileptogenic pathology (dual pathology) were excluded and all patients had been submitted to the same clinical case records and surgical procedure, excluding other influences on outcome. A possible disadvantage of our methodology is the fact that only a single section of hippocampus was analyzed. This section is thought to be representative of all hippocampal pathology, but patterns of HS could vary along the anteroposterior axis of hippocampus in some patients ${ }^{19}$, suggesting a possible pathological bias.

Our data are consistent with previous studies with regard to seizure frequency and age at surgery, suggesting no correlation between them and the pattern of $\mathrm{HS}^{7,20,21}$. Also, duration of epilepsy in our series is suggested to be shorter for patients with normal hippocampus ${ }^{6,7}$. Mean age of epilepsy onset did not show an influence on the patterns of neuronal cell loss, unlike reported by Thom et al. ${ }^{6}$.

IPI, considered as a necessary event to generate the pattern of HS associated with chronic epilepsy, is a central nervous system insult occurring up to six years of age. The controversy over the importance of the age of IPI as a good outcome predictor has been reported ${ }^{6,7}$. In our series, no association between age and type of IPI with severity of hippocampal pathology was found. In this survey, patients with hippocampal neuronal cell loss restricted to CA1 sector (MTS type 2) did not report a history of IPI, which might be due to a small number of cases presenting this pathology.

In our cohort of TLE patients, $72.7 \%$ became seizure-free after surgery, which is consistent with the majority of surgical series in literature ${ }^{22-25}$. The best outcome was achieved by MTS type la and MTS type $1 \mathrm{~b}$ groups, reproducing previous reports $^{6,7}$. In this series, any patients without hippocampal neuronal cell loss (no MTS) have a benefit from epilepsy surgery, contradicting earlier studies in which seizure-free outcome ranged from $44-58 \%^{6,7,15}$. This can be justified by our small number of patients presenting MTS type 2 and normal hippocampal structure.

In conclusion, the analysis of hippocampal neuronal loss patterns immediately after surgery may be used as a predictor of long-term seizure outcome.

\section{ACKNOWLEDGMENTS}

We are grateful for the assistance of Patricia G.A. Ramos in statistical analysis. The authors also thank FAPESP, CNPq and INNT - Instituto Nacional de Neurociência Translacional for supporting this study.

\section{References}

1. Blümcke I, Thom M, Wiestler OD. Ammon's horn sclerosis: a maldevelopmental disorder associated with temporal lobe epilepsy. Brain Pathol 2002;12:199-211.

2. Commission on Classification and Terminology of the International League Against Epilepsy. Proposal for classification of epilepsies and epileptic syndromes. Epilepsia 1989;30:389-399.

3. Wiebe S, Blume WT, Girvin JP, Eliasziw M. A randomized, controlled trial of surgery for temporal-lobe epilepsy. $N$ Engl J Med 2001;345:311-318.

4. Engel JJ, Van Ness P, Rasmussen TB, Ojemann LM. Outcome with respect to epileptic seizures. In: Engel JJ (Ed). Surgical treatment of the epilepsies. New York: Raven, 1993. p. 609-621.

5. Wieser HG, Ortega M, Friedman A, Yonekawa Y. Long-term seizure outcomes following amygdalohippocampectomy. J Neurosurg 2003;98:751-763.

6. Thom M, Liagkouras I, Elliot KJ, et al. Reliability of patterns of hippocampal sclerosis as predictors of postsurgical outcome. Epilepsia 2010;51:1801-1808.
Blümcke I, Pauli E, Clusmann H, et al. A new clinico-pathological classification system for mesial temporal sclerosis. Acta Neuropathol 2007;113:235-244.

8. Mathern GW, Babb TL, Vickrey BG, Melendez M, Pretorius JK. The clinical-pathogenic mechanisms of hippocampal neuron loss and surgical outcomes in temporal lobe epilepsy. Brain 1995;118:105-118.

9. Duvernoy HM. The human hippocampus. Functional anatomy, vascularization and serial sections with MRI. 3rd edition. Heidelberg: Springer, 2005:3-4.

10. Wieser HG, Hane A. Antiepileptic drug treatment before and after selective amygdalohippocampectomy. Epilepsy Res 2003;55:211-223.

11. Aull-Watschinger S, Pataraia E, Czech T, Baumgartner C. Outcome predictors for surgical treatment of temporal lobe epilepsy with hippocampal sclerosis. Epilepsia 2008;49:1308-1316.

12. Engel J, Henry TR, Risinger MW, et al. Presurgical evaluation for partial epilepsy: relative contributions of chronic depth-electrode recordings versus FDG-PET and scalp-sphenoidal ictal EEG. Neurology 1990;40:1670-1677. 
13. Jack CR Jr, Sharbrough FW, Cascino GD, Hirschorn KA, O'Brien PC, Marsh WR.Magneticresonanceimage-based hippocampalvolumetry:correlation with outcome after temporal lobectomy. Ann Neurol 1992;31:138-146.

14. Kilpatrick C, Cook M, Kaye A, Murphy M, Matkovic Z. Non-invasive investigations successfully select patients for temporal lobe surgery. J Neurol Neurosurg Psychiatry 1997;63:327-333.

15. de Lanerolle NC, Kim JH, Williamson A, et al. A retrospective analysis of hippocampal pathology in human temporal lobe epilepsy: evidence for distinctive patient sub-categories. Epilepsia 2003;44:677-687.

16. Nakasato N, Lévesque MF, Babb TL. Seizure outcome following standard temporal lobectomy: correlation with hippocampal neuron loss and extra hippocampal pathology. J Neurosurg 1992;77:194-200.

17. Sagar HJ, Oxbury JM. Hippocampal neuron loss in temporal lobe epilepsy: correlation with early childhood convulsions. Ann Neurol 1987;22:334-340.

18. Wyler AR, Dohan FC, Schweitzer JB, Berry AD. A grading system for mesial temporal pathology (hippocampal sclerosis) from anterior temporal lobectomy. J Epilepsy 1992;5:220-225.

19. Thom M, Sisodiya SM, Beckett A, et al. Cytoarchitectural abnormalities in hippocampal sclerosis. J Neuropathol Exp Neurol 2002;61:510-519.
20. Davies KG, Hermann BP, Dohan FC Jr, Foley KT, Bush AJ, Wyler AR. Relationship of hippocampal sclerosis to duration and age of onset of epilepsy, and childhood febrile seizures in temporal lobectomy patients. Epilepsy Res 1996;24:119-126.

21. Mathern GW, Babb TL, Mischel PS, et al. Childhood generalized and mesial temporal epilepsies demonstrate different amounts and patterns of hippocampal neuron loss and mossy fibre synaptic reorganization. Brain 1996;119:965-987.

22. Bien CG, Kurthen M, Baron K, et al. Long-term seizure outcome and antiepileptic drug treatment in surgically treated temporal lobe epilepsy patients: a controlled study. Epilepsia 2001;42:1416-1421.

23. Clusmann H, Schramm J, Kral T, et al. Prognostic factors and outcome after different types of resection for temporal lobe epilepsy. J Neurosurg 2002;97:1131-1141.

24. Hildebrandt M, Schulz R, Hoppe M, May T, Ebner A. Postoperative routine EEG correlates with long-term seizure outcome after epilepsy surgery. Seizure 2005;14:446-451.

25. Janszky J, Janszky I, Schulz R, et al. Temporal lobe epilepsy with hippocampal sclerosis: predictors for long-term surgical outcome. Brain 2005;128:395-404. 